\title{
MICROSCOPIC FEATURES OF CEMENT PASTE MODIFIED BY FINE PERLITE
}

\author{
Vladimír HrbeK $^{a, *}$, Veronika Koudelková ${ }^{b}$, Pavel PadevěT $^{a}$, \\ PETR ŠAŠEK ${ }^{b}$ \\ ${ }^{a}$ Czech Technical University, Thakurova 6, Prague 6, Czech Republic \\ ${ }^{b}$ Institute of Theoretical and Applied Mechanics AS CR, v.v.i., Prosecka 76, Prague 9, Czech Republic \\ * corresponding author: vladimir.hrbek@fsv.cvut.cz
}

\begin{abstract}
The use of waste material and replacement of binder element in cementitious composites is in focus of material development. Perlite in the construction industry is usually used in form of lightweight aggregate enhancing the insulating performance of concrete. This paper focuses on integration of fine perlite into the cement matrix and possible replacement of the cement binder in the composition of the material. The macromechanical performance of the modified paste is tested on specimens with 5,10,15 and $20 \%$ fine perlite substitution and pure cement sample. To distinguish the effect of the perlite on the microstructural level, pure cement material and specimen containing $10 \%$ of fine perlite are investigated by the electron microscopy. Furthermore, the mechanical properties of individual phases are examined and compared on same samples by instrumented indentation. The presented results enabled estimation of fine perlite impact on the macro and microscopic performance of the material.
\end{abstract}

KEYWORDS: perlite, SEM, nanoindentation, mechanical properties.

\section{IntRoduCtion}

Reduction of energy consumption and $\mathrm{CO}_{2}$ emissions production is the important challenge in the concrete industry at the present time, thus the focus on the utilization of different waste material partly replacing cement binder plays the key role in the field of research [1. Among supplementary materials perlite represents an expanded natural material produced through loosing water during heating of source material - hydrous volcanic glass. Most frequently is perlite with its porous structure used as a filler in the lightweight concretes. Moreover, it also improves concrete insulation properties and fire resistance. Processing of the crude natural volcanic material and the production of perlite lead into creation of perlite fines currently considered as the waste material 22. The quality of concrete containing fine perlite is possible to asses from micro as well as from macro aspects. The most important phenomenon observable on the microscale is pozzolanic activity of perlite fines since creation of chemical bond between perlite particles and surrounding binder is crucial in developing proper mechanical properties of the cementitious mixture. The second important parameter is the total volume of fine perlite in cement which influences the mechanical behavior of cement composite. Yu et. al 3] determined the most effective perlite content equal to $15 \%$ since it significantly improved the compressive strength of concrete (about $16 \mathrm{MPa}$ higher than in the case of concrete without perlite fines addition). Similar results obtained Rózycka and Pichór [4] during testing of perlite waste addition effect on the proper- ties of autoclaved aerated concrete. The compressive strength didn't significantly changed up to $30 \%$ of volume addition of perlite waste particles. On the contrary Oktay et. al [5] determined that the highest compressive strength showed the concrete specimens with no addition of expanded perlite. The results mentioned above [3 3 ] confirms the importance of chemical availability of perlite particles resulting in creation of interface between perlite and surrounding binder. Hence, this paper is aimed at the investigation of macroscopic and microscopic mechanical properties of cementitious paste containing different volume $(5,10,15$ and $20 \%)$ of crushed fine perlite particles. The results of macroscopic testing determined samples for microscopical evaluation, where specimen with $10 \%$ substitution of perlite is compared to pure cement paste. The microstructure is observed implementing the scanning electron microscope (SEM), which enables defining different chemical phases and their interfaces in the material. The micromechanical properties of individual phases are determined from histograms of the results provided by instrumented indentation.

\section{Materials and Methods}

The macroscopic specimens were prepared from ordinary Portland cement CEM I 42.5R mixture with water to cement ratio 0.35 . The composition according to declaration of fine perlite producer is summarized in Table 1. The specimens were placed in $40 \times 40 \times 160 \mathrm{~mm}$ forms, cast out 24 hours after mixing and stored until 28 days of total age in water 
to prevent the carbonation. The sets of specimens are denoted as ModCem x.xx, where x.xx stands for the fine perlite percentage substitution and specimen ModCem 0.00 served as reference sample (pure cement paste). The residues from macroscopic testing were embedded in epoxy resin and used for microscopic investigation. The samples were sectioned by diamond cut-off wheel and the surface grinded and polished using silica-carbon papers (grid roughness P1200, P2400 and P4000 according to European P-grade system) and the $3 \mu \mathrm{m}$ diamond suspension.

\begin{tabular}{lccc}
\hline \multicolumn{1}{l}{ Chemical content } & \multicolumn{2}{l}{ Granulometry } \\
\hline $\mathrm{SiO}_{2}$ & $\min 66 \%$ & $>0.2 \mathrm{~mm}$ & $\max 10 \%$ \\
\hline $\mathrm{Al}_{2} \mathrm{O}_{3}$ & $\max 18 \%$ & $>0.1 \mathrm{~mm}$ & $\min 50 \%$ \\
\hline $\mathrm{Fe}_{2} \mathrm{O}_{3}$ & $\max 3 \%$ & $<0.1 \mathrm{~mm}$ & $\max 50 \%$ \\
\hline $\mathrm{CaO}+\mathrm{MgO}$ & $\max 6 \%$ & & \\
\hline $\mathrm{Na}_{2} \mathrm{O}+\mathrm{K}_{2} \mathrm{O}$ & $\max 8 \%$ & & \\
\hline
\end{tabular}

TABle 1. Composition of used fine perlite.

\subsection{Macromechanical testing}

To determine macromechanical properties i.e. bending strength and compressive strength, 6 macroscopic specimens $(40 \times 40 \times 160 \mathrm{~mm}$ dimensions $)$ were tested from each type of cement mixture. Tensile stresscapacity was determined from load-controlled threepoint bending test with support spacing of $100 \mathrm{~mm}(l)$ from the Equation 1 . where $F_{T}$ is maximum applied force causing bending moment, $b$ and $h$ are dimensions of sample cross-section.

$$
\sigma_{\mathrm{T}}=\frac{3}{2} \frac{F_{\mathrm{T}} l}{b h^{2}}
$$

Compressive strength of samples was determined by load-controlled compression test with pressure pad area of $40 \times 40 \mathrm{~mm}$ and calculated according the Equation 2 where $F_{C}$ is maximum applied compressive force and $A$ is the pressure pad area $(40 \times 40 \mathrm{~mm})$.

$$
\sigma_{\mathrm{C}}=\frac{F_{\mathrm{C}}}{A}
$$

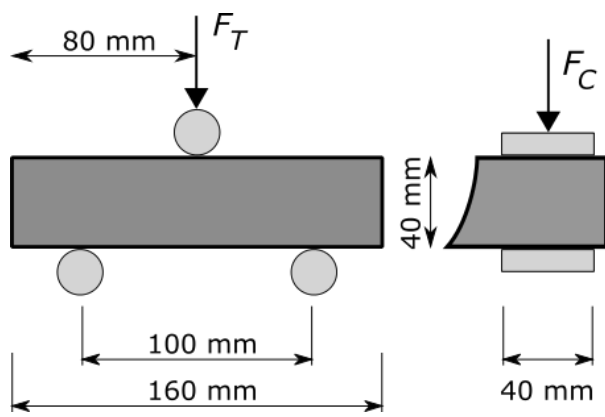

Figure 1. Macroscopic tests setting - three-point bending (left), compression (right).

\subsection{SEM}

SEM investigation was performed in MIRA II LMU (Tescan corp., Brno) on polished specimens coated with thin layer of carbon necessary to ensure proper conductivity of the surface. Working distance of the microscope was set closely to $15 \mathrm{~mm}$ and accelerating voltage was set to $15 \mathrm{kV}$ - to provide good signal. The micrographs were acquired at different magnifications. Each specimen was investigated at first at the magnification $600 \times$ to gain good overview and than at higher magnifications (above $1200 \times$ ) for better study of different phases in detail. SEM micrographs acquired with back scattered electron detector (BSE) provide information about distribution and chemical composition of different phases since back scattering coefficient strongly depends on the atomic number Z

\subsection{NANOINDENTATION}

To determine micromechanical properties, instrumented grid indentation using nanoindenter Ti 750 serie (Hysitron Inc.) was performed on the polished specimens with high surface quality. In this technique mechanical properties are calculated from the unloading part of the force-displacement dependency diagram. One of the most important parameter which can be directly calculated is hardness $\mathrm{H}$ defined as pressure the maximum force $\left(\mathrm{P}_{\max }\right)$ under the contact area of the tip $\left(A_{c}\right)$.

$$
\mathrm{H}=\frac{P_{\max }}{A_{\mathrm{C}}}
$$

The reduced (effective) elastic modulus $\left(\mathrm{E}_{\mathrm{r}}\right)$ of measured volume of the material follows from the relationship between the unloading stiffness $(\mathrm{S})$ and contact area with respect to the probe geometry $(\beta)[6$.

$$
\mathrm{E}_{r}=\frac{\sqrt{\pi}}{2 \beta} \frac{S}{\sqrt{A_{\mathrm{C}}}}
$$

A grid indentation of $10 \times 10$ pattern with equally spaced indents (30 $\mu \mathrm{m}$ separation) was used in order to cover sufficient area containing all material phases. The load-controlled protocol of indentation consisted of loading - holding - unloading parts lasting 5 - 25 - 5 seconds respectively and reaching maximum applied force of $2.5 \mathrm{mN}$. To obtain proper statistical set of measured data, four grid indentations were performed on different places of each sample. Mechanical properties of individual phases in the heterogeneous cement paste can be obtained from the histograms with equally spaced bins of the examined property by statistical deconvolution [7, 8]. In this paper, we assess the properties of individual phases based on difference between histograms of indentation results of modified cement paste (ModCem 0.10) and referential specimen (ModCem 0.00). 


\section{Results}

\subsection{ThrEe-POINT BENDING, COMPRESSION}

The results of macromechanical testing (Table 2) correspond with results presented by Oktay et. al [5], i.e. referential pure cement samples reach the highest values of compressive $(81.89 \pm 9.68 \mathrm{MPa})$ and tensilestress capacity $(1.50 \pm 0.83 \mathrm{MPa})$. Mod/Ref value present deviation of specimen mechanical property from referential sample. At this preliminary stage of research, perlite modification of cement paste with similar macromechanical performance was in focus. According to Table 2 specimens containing $10 \%$ of fine perlite substitution (ModCem 0.10) exhibit lowest decrease of both compressive and tensile-stress capacity (about $8 \%$ and $4 \%$ respectively). This led to selection of ModCem 10 sample for microscopic investigation of the material.

\begin{tabular}{llcc}
\hline \multicolumn{3}{l}{ Compressive strength } \\
\hline $\begin{array}{l}\text { Specimen } \\
\text { denotion }\end{array}$ & Mean & $\begin{array}{c}\sigma_{\mathrm{C}}[\mathrm{MPa}] \\
\text { Stat.dev. }\end{array}$ & Mod/Ref \\
\hline ModCem 0.00 & 81.89 & 9.68 & 1.00 \\
\hline ModCem 0.05 & 64.01 & 13.28 & 0.78 \\
\hline ModCem 0.10 & 76.04 & 10.84 & 0.93 \\
\hline ModCem 0.15 & 64.69 & 5.42 & 0.79 \\
\hline ModCem 0.20 & 70.80 & 11.32 & 0.87 \\
\hline Tensile strength & & \\
\hline $\begin{array}{l}\text { Specimen } \\
\text { denotion }\end{array}$ & Mean & Stat.dev. & Mod/Ref \\
\hline ModCem 0.00 & 1.50 & 0.83 & 1.00 \\
\hline ModCem 0.05 & 1.36 & 0.63 & 0.91 \\
\hline ModCem 0.10 & 1.45 & 0.52 & 0.97 \\
\hline ModCem 0.15 & 1.57 & 0.34 & 1.05 \\
\hline ModCem 0.20 & 1.56 & 0.30 & 1.04 \\
\hline
\end{tabular}

TABLE 2. Macromechanical test results.

\subsection{SEM INVESTIGATION}

The SEM equipped with energy dispersive X-ray detector (EDX) enables to distinguish different phases in the studied cementitious materials (ModCem 0.00, ModCem 0.10). Based on the BSE micrographs and EPMA (electron probe microanalysis - using EDX) was possible to determine five phases - clinker, CSH gels, portlandite (calcium hydroxide - $\mathrm{CH}$ ), pores and perlite particles (see in the Figure 2).

Clinkers in the gray-scaled BSE micrographs represent the most intensive particles because of their dense structure and high iron and calcium content. Around clinker particles is possible to determine darker well defined area called high density calcium-silica-hydrate gel (HD-CSH) as a result of progressive slow hydration of non-hydrated clinker cores. The HD-CSH gel represent the first one modification of $\mathrm{CSH}$, the second one is low density CSH gel (LD-CSH) with more opened porous structure.

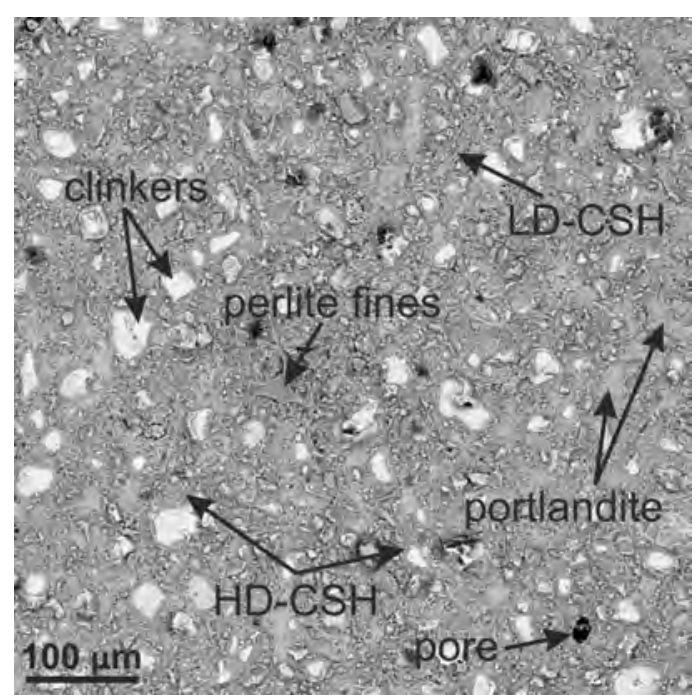

FigURE 2. BSE micrograph showing microstructure of cement paste with perlite addition.

The size of perlite was variable - from approximately $200 \mu \mathrm{m}$ of undamaged whole particles to perlite fines i.e. internal lamella of perlite with various size. The interface between undamaged perlite particles and surrounding cement matrix was sharp and didn't show in most cases any chemical reaction detectable at microscale in the SEM (Figure 4). Nevertheless, according to literature perlite fines are considered as good pozzolanic material 3. In our investigation chemical reaction between crushed internal lamella and cement was observed in the specimen ModCem 0.10. The evident structural disintegration coupled with decreasing content of Si in affected perlite lamella is demonstrated in the Figure 3

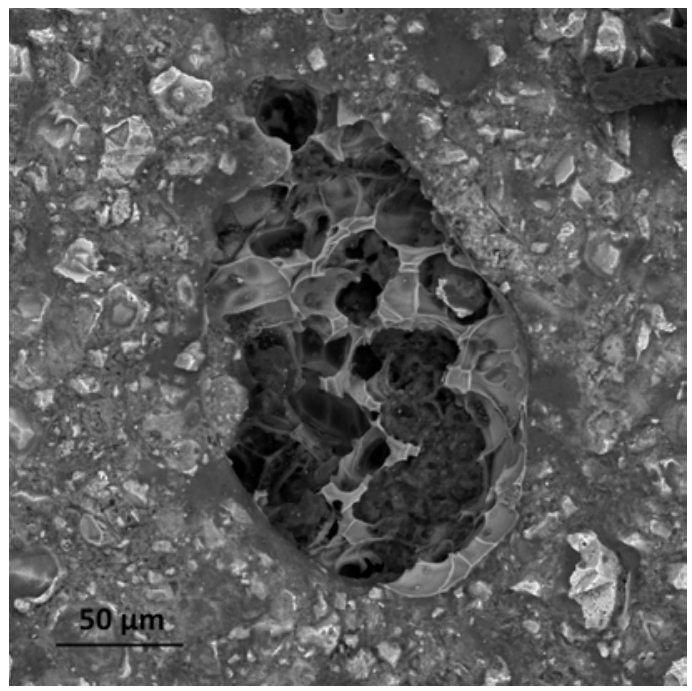

FigURE 4. BSE micrograph showing microstructure of cement paste with perlite addition. 

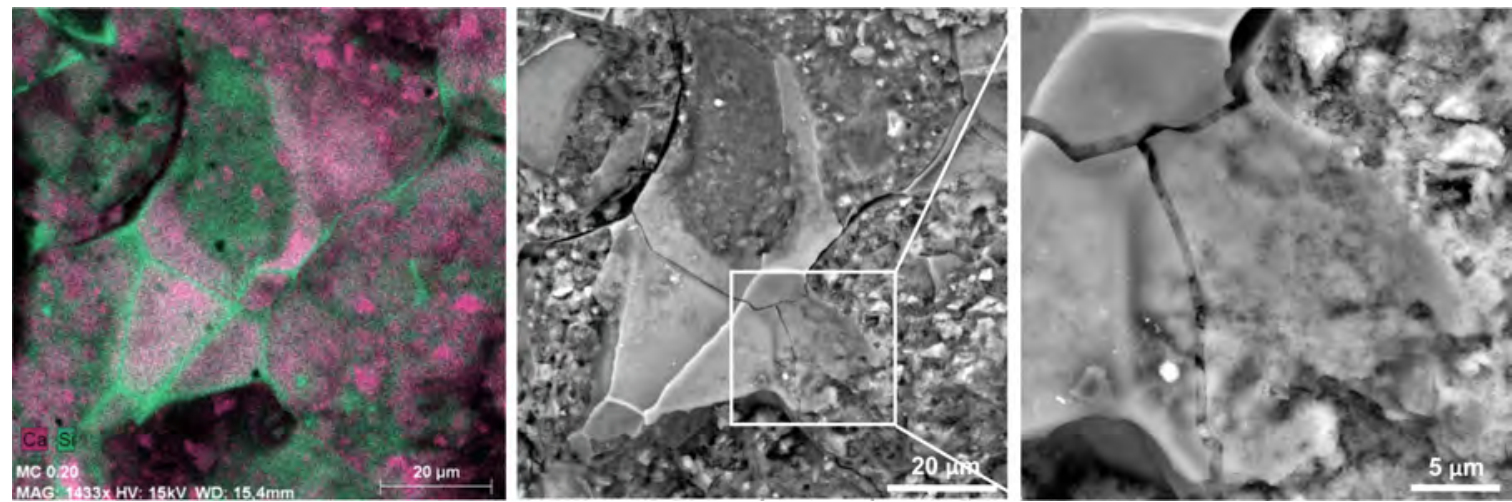

FiguRE 3. SEM - EDS of integrated perlite fines - Si content decrease and detail of lamella integration.

The decreasing tendency of Si content can be also presented on EPMA with EDX analysis results of perlite lamella and cement matrix boundary. Figure show positions of testing and Table describes weight percentage containment (wpc) of individual elements in each position of interest. Position 4 with Si containment $10.55 \%$ of weight correspond to $\mathrm{CSH}$ phases and Position 8 (Si wpc 16.31\%) to pure perlite [9].

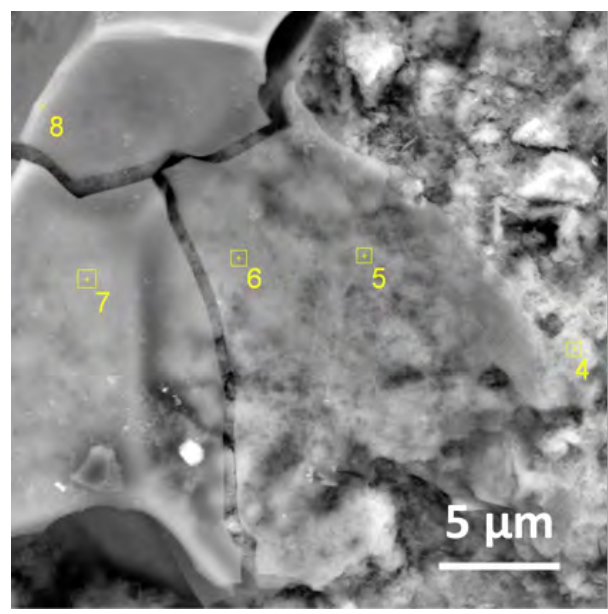

FiguRE 5. EPMA - EDX of perlite lamella and cement.

\begin{tabular}{lrrrrr}
\hline Pos & \multicolumn{1}{c}{$\mathbf{8}$} & \multicolumn{1}{c}{} & \multicolumn{1}{c}{$\mathbf{6}$} & \multicolumn{1}{c}{$\mathbf{5}$} & \multicolumn{1}{c}{} \\
\hline $\mathrm{Ca}$ & 9.80 & 27.61 & 23.49 & 23.25 & 23.91 \\
\hline $\mathrm{Si}$ & 16.31 & 15.38 & 13.96 & 11.39 & 10.55 \\
\hline $\mathrm{Al}$ & 3.11 & 2.88 & 3.34 & 2.27 & 4.22 \\
\hline $\mathrm{Mg}$ & 0.05 & 0.06 & 0.23 & 0.19 & 0.21 \\
\hline $\mathrm{K}$ & 4.09 & 1.75 & 4.29 & 4.65 & 5.28 \\
\hline $\mathrm{Na}$ & 0.76 & 1.26 & 1.12 & 0.80 & 0.73 \\
\hline $\mathrm{S}$ & 0.30 & 0.40 & 0.36 & 0.71 & 0.42 \\
\hline $\mathrm{Fe}$ & 1.17 & 0.51 & 0.86 & 0.82 & 1.22 \\
\hline $\mathrm{O}$ & 64.42 & 50.15 & 55.85 & 55.91 & 53.47 \\
\hline
\end{tabular}

TABLE 3. EPMA - EDX chemical elements analysis (weight percentage containment in \%).

\subsection{INSTRUMENTED INDENTATION}

The previously described phases of the material (LD $\mathrm{CSH}, \mathrm{HD} \mathrm{CSH}, \mathrm{CH}$ and clinker) and their mechanical properties (reduced modulus) can be observed in the indentation histogram. The LD CSH forms a significant peak close to $30 \mathrm{GPa}$, which is consistent with previous research $(21.7 \pm 2.2 \mathrm{GPa}$ [7, 8, 10]). Measured indentation modulus of the HD CSH phase is close to $40 \mathrm{GPa}$ (occurrence of peaks in range 35 to $50 \mathrm{GPa}$ ) and the $\mathrm{CH}$ reaches up to $60 \mathrm{GPa}$, according to the Figure 6. More accurately, using statistical deconvolution, reduced modulus estimation reach $27.34 \pm 2.56$ for LD CSH phase, $39.29 \pm 4.11 \mathrm{GPa}$ for $\mathrm{HD} \mathrm{CSH}$ phase and $61.54 \pm 4.30 \mathrm{GPa}$ for $\mathrm{CH}$ phase. Compare to phase reduced modulus measured on samples with w/c ratio $0.5(29.4 \pm 2.4 \mathrm{GPa}), \mathrm{HD} \mathrm{CSH}$ phase reaches peak of indentation modulus naturally higher due to lower $\mathrm{w} / \mathrm{c}$ ratio. The clinker phase is not in focus of this study due to its high stiffness and interference with other "low stiffness" phases, which misrepresent the result of indentation (collected data above $90 \mathrm{GPa}$ are therefore excluded).

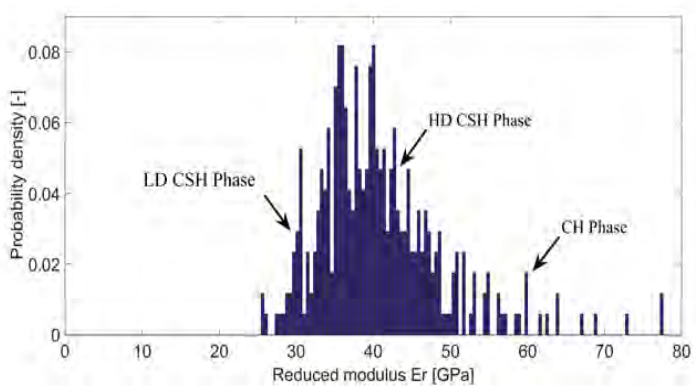

Figure 6. ModCem 0.00 - Reduced modulus histogram.

Figure7 represents the indentation data measured on specimen ModCem 0.10. Significant peaks of the cementitious matrix are slightly shifted to lower values due to the interaction of fine perlite residues to the composite structure and formation of "low stiffness" phase. The formation is not yet known to authors and will be subjected to further investigation. The 
individual phases of the cement form the peaks around $25 \mathrm{GPa}$ for LD CSH phase, $33 \mathrm{GPa}$ for HD CSH and $49 \mathrm{GPa}$ in case of $\mathrm{CH}$ phase. The Young's modulus of expanded perlite is assumed to be equal 20 GPa [11, 12], which correspond to the peak found in the histogram. There is very significant peak formed around $10 \mathrm{GPa}$, which the authors have not been able to identify yet. The lower indentation modulus of all phases in modified cement paste also explains the decrease of macroscopic performance of the composite.

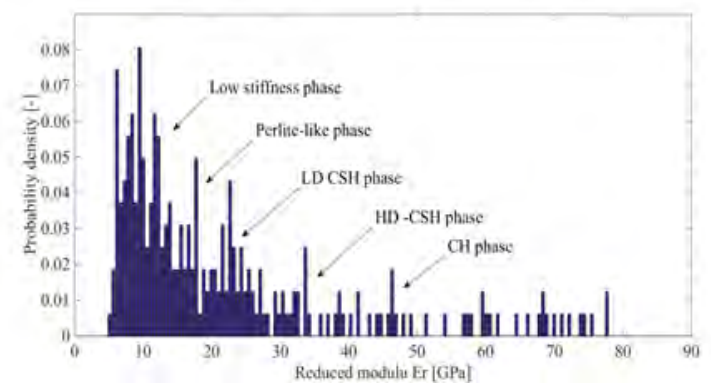

Figure 7. ModCem 0.10 - Reduced modulus histogram.

\section{Conclusions}

Cementitious composite with substitution of fine perlite was investigated on macro and microscopical level. The macro mechanical testing of specimens showed slight decrease of material strength for all cases of cement replacement. The lowest decrease was observed on ModCem 0.10, which was thus tested on microscopical level. The investigation of microstructure with SEM proved the interaction of fine perlite lamella with cement matrix and integration of whole perlite particles. The instrumented indentation enabled to identify impact of cement paste modification due to comparison of referential data and reduced modulus of phases in specimen ModCem 0.10. More detailed interaction of fine perlite and cement composite will be further researched.

\section{LIST OF SYMBOLS}

$\sigma_{T}$ Bending strength $[\mathrm{MPa}]$

$F_{T} \quad$ Maximum applied force causing bending moment $[\mathrm{N}]$

$b \quad$ Specimen cross section width $[\mathrm{m}]$

$h$ Specimen cross section height $[\mathrm{m}]$

$\sigma_{C}$ Compressive strength [MPa]

$F_{C}$ Maximum applied compressive force $[\mathrm{N}]$

$A$ Pressure pad area $\left[\mathrm{m}^{-2}\right]$

$l \quad$ Spacing of supports $[\mathrm{m}]$

$H$ Hardness [GPa]

$P_{\max }$ Maximum force $[\mathrm{Pa}]$

$A_{c}$ Contact area under the tip $\left[\mathrm{nm}^{-2}\right]$

$E_{r}$ Reduced elastic modulus [GPa]

$\beta$ Probe geometry constant [-]

$S$ Stiffness $\left[\mathrm{Nm}^{-1}\right]$

\section{ACKNOWLEDGEMENTS}

The research has been supported by Czech Science Foundation (Project no. P105/12/G059).

\section{REFERENCES}

[1] Paris J.M., Roessler J.G., Ferraro C.C., DeFord H.D., Townsend T.G., A review of waste products utilized as supplement to Portland cement in concrete. J Clean

Product 121:1 - 18, 2016.

DOI: $10.1016 /$ j.jclepro.2016.02.013

[2] Kotwica L., Pichór W., Nocún-Wczelik W., Study of pozzolanic action of ground waste expanded perlite by means of thermal methods. J Therm Anal Calor

123:607 - 613, 2016 .

DOI: $10.1007 / \mathrm{s} 10973-015-4910-8$

[3] Yu L.H., Ou H., Lee L.L., Investigation on pozzolanic effect of perlite powder in concrete. Cem Con Res 33:73 - 76, 2003.

DOI: $10.1016 / \mathrm{s} 0008-8846(02) 00924-9$

[4] Rózycka A., Pichór W., Effect of perlite waste addition on the properties of autoclaved aerated concrete. Const Built Mat 120:65 - 71, 2016. DOI: $10.1016 /$ j.conbuildmat.2016.05.019

[5] Oktay H., Yumrutas R., Akpolat A., Mechanical and thermophysical properties of lightweight aggregate concretes. Const Built Mat 96:217 - 225, 2015. DOI: $10.1016 /$ j.conbuildmat.2015.08.015

[6] Oliver W.C., Pharr G.M., Measurement of hardness and elastic modulus by instrumented indentation: Advances in understanding and refinements to methodology. J Mat Res 19:3 - 20, 2004. DOI: $10.1557 /$ jmr.2004.0002

[7] Constantinides G., Chandran K.R., Ulm F.J., Vliet K.V., Grid indentation analysis of composite microstructure and mechanics: Principles and validation. Mat Sci Eng A 430:189 - 202, 2006. DOI: $10.1016 /$ j.msea.2006.05.125

[8] Němeček J., Vondřejc J., Králík V., Micromechanical analysis of heterogeneous structural materials. Cem Con Com 36:85 - 92, 2013.

DOI: $10.1016 /$ j.cemconcomp.2012.06.015

[9] Kabra S., Katara S., Rani A., Characterization and study of Turkish perlite. Inter J Innovative Res Sci, Eng and Techno 2:4319 - 4326, 2013.

ISSN: $2319-8753$

[10] Velez K., Maximilien S., Damidot D., Fantozzi G., Sorrentino F., Instrumented Determination by nanoindentation of elastic modulus and hardness of pure constituents of Portland cement clinker. Cem Con Res 31:555 - 561, 2001.

DOI: 10.1016/S0008-8846(00)00505-6

[11] Sengul O.,Azizi S.,Karaosmanoglu F.,Ali M., Effect of expanded perlite on the mechanical properties and thermal conductivity of lightweight concrete. Energy Build 43:671 - 676, 2011.

DOI: $10.1016 / \mathrm{j}$.enbuild.2010.11.008

[12] Abidi S., Joliff Y.,Favotto C., Impact of perlite, vermiculite and cement on the Young modulus of a plaster composite material: experimental, analytical and numerical approaches. Compos. B 92:281 - 36, 2016. DOI: $10.1016 /$ j.compositesb.2016.02.034 